\title{
A Framework for Developing Social Networks Enabling Systems to Enhance the Transparency and Visibility of Cross-border Food Supply Chains
}

\author{
Frank J. Xu, Victor P. Zhao, Lu Shan, Chuxiong Huang
}

\section{Received 08 Nov 2013 Accepted 19 Dec 2013}

\begin{abstract}
Demands on safe, high-quality and healthy food are unprecedentedly increasing in both emerging economies and advanced countries. Food safety incidents and scandals, frequently breaking out around the world, are significantly reducing the confidence of consumers in food safety and quality. It is even more difficult to achieve the full transparency, visibility and traceability of dynamic cross-border and global food supply chains, which is critical to ensure food safety and quality, due to: the personalization and globalization of consumer demands; the diversities of food products, raw materials and ingredients; the loose relationships between food business partners; the technology and resource barriers in aligning business processes, coordinating and sharing information; and the changing government supervision mechanisms and standards. Social networking technologies and social software are promising enablers to facilitate end consumers, food companies and government agencies to participate in open discussion, comments and feedback on the quality and safety of cross-border foods. They are able to connect, interact, communicate and collaborate with each other in loose, open, effective and flexible ways for enhancing the transparency and visibility of cross-border and global food supply chains through collective wisdom and intelligence. In this paper a framework is proposed for developing social networks enabling food traceability systems, which not only leverages enterprise
\end{abstract}

Manuscript received November 8, 2013. This work was supported in part by the Guangdong Science and Technology Innovation Fund administered by Guangdong Provincial Department of Science and Technology of China under the Programme of Guangdong-Hong Kong Breakthrough Project in Key Areas (The project reference number: 2011A011303004), and by Shenzhen Strategic Emerging Industry Development Fund (The project reference number: ZDSY20120615142741201).

Frank J. Xu was with the E-Business Technology Institute, The University of Hong Kong. He is now with the Department of Civil Engineering, The University of Hong Kong. He is also a member of Shenzhen Institute of Research and Innovation and Shenzhen Key Lab in Carbon Emission Enabling Technologies, The University of Hong Kong (corresponding author, phone: 852-2241-5791; fax: 852-2559-5337; e-mail: frankxu@ hku.hk)

Victor P. Zhao is with the Emerging Technologies Institute (formerly as E-Business Technology Institute), The University of Hong Kong (e-mail: vzhao@eti.hku.hk). He is also a member of Shenzhen Institute of Research and Innovation and Shenzhen Key Lab in Carbon Emission Enabling Technologies, The University of Hong Kong. He is currently a PhD candidate of Shanghai University of Finance and Economics, China.

Lu Shan is with Guangzhou Wanglaoji Pharmaceutical Company Limited, China (e-mail: shanlu@wlj.com.cn).

Chuxiong Huang is with Guangzhou Wanglaoji Pharmaceutical Company Limited, China (e-mail: huangcx@wlj.com.cn) applications, public service platforms for food quality, safety and traceability operated by government or industrial associations, but utilizes such emerging technologies as Internet-of-Things, social analytic and mobile technologies to ease interactive communication and collaboration between various stakeholders of food chains. Guidelines, architectures, use scenarios, and technology alternatives for implementing the traceability systems are also discussed in this work. A prototype, titled $O S C M-F D$, is being implemented and pilots are being conducted to verify the validity of the proposed framework.

Index Terms-Food Safety and Quality, Food Supply Chain, Social Applications, Social Network, Transparency, Traceability System

\section{INTRODUCTION}

Food industry is facing great challenges and pressures in managing its dynamic, globalized and complex supply chain for providing consumers with safe, high-quality, healthy and environment friendly products and satisfying more rigorous requirements of food laws and regulations [5], [12], [20], [38], [44] , [53], [63] , [67]. Consumers are demanding more detailed information on the food they consume each day, from recipes, the origins of raw materials and ingredients, through certified quality, safety and nutrition labels, processes of food planting or live stocks breeding, production, processing, packaging and distribution, pesticide residue level, to environmental impacts and the comments from friends on food tastes [31], [33]. International organizations, non-government and government organizations, and industry consortiums have been pursuing the enforcement and reform of variable food guidelines, standards and legislations, promoting or forcing food producers, logistics providers and retailers to adopt specific management and operation practices, to safeguard food quality and safety [19]. Food companies are struggling to pilot innovative business practices and implement emerging technologies to establish flexible and efficient collaborations with upstream and downstream partners for sharing tracking and tracing information, thus improving the efficiency and transparency of their supply chains [3], [10], [16-18], [24], [49].

Globalization, personalized food consumption behavior, and unprecedentedly increasing demands on quality and healthy foods from both developed countries and emerging economies 
are imposing significant complexities and rising costs for achieving horizontal and vertical transparency in local or cross-border/global, 'closed' or 'open' food supply chains [63], [67]. Worldwide food and agricultural export had doubled to US\$900 billion in 2007 compared to US\$400 billion in 2000, which continues to increase [74]. This growth means that impacts of food safety incidents have not been confined in a relatively small area more, rather than can disseminate easily across country and continent borders. For example, to make the world's best-selling organic yogurt, Stonyfield Farm usually needs to source the product's raw ingredients globally, importing organic milk powder from New Zealand, strawberries from China, apple puree from Turkey, blueberries from Canada, and bananas from Ecuador [7]. Establishing such a kind of global supply chain network is a better way to keep the business growing, but a weaker way to maintain the safety, security and resilience of food chains. It is very hard to enforce consistent safety and organic standards, to harmonize supervision and trade mechanisms across different countries and regions. In the largest developing and emerging economies, the so-called BRIIC: Brazil, China, India, Indonesia, and Russia, economic and population growth and rising incomes have changed consumers' demands on food categories, food varieties and food qualities [1]. Less mature regulations and systems for food quality and safety control in these countries lead to higher risk of food safety incidents occurrence.

Visibility and transparency of cross-border and global food supply chains have been realized only at limited stages for limited categories of food by now. Cross-border consumers and food supply chain stakeholders aren't able to acquire and share consistent, complete, accurate and timely food quality tracking and tracing information. In recent years, cross-border food shopping and consumption between cities in Pearl River Delta region and Hong Kong has become a trend-Hong Kong imports $94 \%$ of fresh pork, $100 \%$ of fresh beef, $92 \%$ of vegetables and $66 \%$ of eggs from China [77]; Infant formula and baby dairy foods have become the must buy items for most of Chinese tourists to Hong Kong. Though Hong Kong and the Mainland authorities have established emergency working mechanisms and jointly developed pilots systems for ensuring the quality, safety and stability of cross-border food products, high time and financial cost has to to be paid to align cross-border supervision regulations and processess, and to harmonize cross-company operations. The cross-border food chains are fragile. In addition, cross-border consumers are not fully motivated in participating in the monitoring of food safety, quality and sustainability; they need convenient channels to communicate with food companies and governments for sharing consumption experiences, reporting adverse food responses-important information sources from which to identify consumers' personalized requirements and detect food safety accidents, and obtaining food recall information.

Frequently outbreaking food safety incidents, crises and scandals around the world in recent years, such as E. coli outbreak in Germany linked to imported cucumbers in 2011, Salmonella Saintpaul outbreak in fresh produce in the United States in 2008, plasticizer contamination scandal in Taiwan in 2011, have eroded consumers' trust and confidence in current local and global food supply chain. According to the report released by Food Marketing Institute in 2007, the number of consumers "completely" or "somewhat confident" in the safety of supermarket food declined from 82 percent in 2006 to 66 percent in 2007, even lower to 43 percent in restaurant food [88]. Delottie's 2011 survey reveals that $73 \%$ of respondent consumers are more concerned now than five years ago about the food they eat [12]. A series of food accidents recently occurring in China, such as counterfeit baby formula, melamine-tainted milk powder, cooking oil, additives in pork and chemicals in steamed buns have spurred public outrage and are even threatening the nation's economic development and social stability [86], [87]. Stakeholders of food supply chain are summing up lessons from these incidents to restore consumers' confidence in food chain. More transparency and visibility of the whole life-cycle chain and wider public participation is the key; technology innovation is one of critical promising enablers, besides reform of government supervision organizations and regulations and optimization of food supply chain business processes.

Various enterprise applications - enterprise resource planning system (ERP), warehouse management system (WMS), transportation management system (TMS), to name only a few, food quality management systems, government supervision systems, public tracking and tracing service platforms, together with sensing, labeling, data capturing and exchanging technologies, such as linear and quick response $(\mathrm{QR})$ barcodes, radio frequency identification (RFID), temperature and humidity sensors, global position system (GPS), eXtended Markup Language (XML), Web Service, DNA fingerprinting, have been being deployed and piloted around the world, though not universally and evenly used yet, to improve the transparency and visibility of complex food supply chains [53], [63], [67]. Most of these systems are implemented only for governments to simplify supervision and administration processes, for big food companies or retailers to align operation processes with their closed business partners under strict agreement terms of sharing and using tracking and tracing data. They have very limited functions to support open, transparent, dynamic, loose but flexible interactions and collaborations between consumers and food companies, consumers and governments, cross-border governments, food manufacturers, traders, distributors, retailers and governments involved in cross-border food supply chains.

Social software and social networking technologies, great enablers for supporting open participation and collaboration of loosely connected individuals, customers, partners, enterprises and government organizations, are increasingly being adopted in various business contexts and in a broad range of vertical industries [39]. Originating as tools to connect with friends and family, Facebook, Twitter and Sina Weibo-like social network sites have already evolved into a comprehensive platform, through which enteprises are able to do marketing promotion, to manage customer and partner relationships, and to execute business processes and transactions; government agencies are able to manage social crises and public health emergency [39], [82][83].

But, the use of social software and social networking technologies is not thoroughly studied in the context of food quality and safety managment, tracking and tracing of cross-border food products. This research aims to bridge this gap by proposing a framework for developing social networks enabling systems to enhance the transparency and visibility of 
cross-border and global supply chains. The framework will facilitate loosely connected stakeholders of cross-border and gobal supply chains to embed social networking technologies into their existing applications or develop new traceability system for working collectively and closely to achieve higher levels of visibilty and transparency.

The rest of the paper is organized as follows. Prior works are reviewed shortly in section II on the complexity and challenges of achieving transparency of cross-border and global food supply chains, tracking and tracing systems and platforms for food safety and quality managment, and current applications of social networking technologies in business enterprises and government. Section III presents the proposed framework for developing social networks enabling systems to enhance the transparency and visibility of cross-border and global supply chains, together with implementation alternatives of the framework. A prototype of social networks-enabling visibility system for Guangdong-Hong Kong cross-border food supply chain management, titled Open Tracking and Tracing System for Guangdong-Hong Kong Food and Drug Supply Chain Management (OSCM-FD), is being developed based on the framework. Section IV discusses the architecture of OSCM-FD system, use scenarios and pilots we plan to conduct using the system. Challenges and open questions for using the proposed framework and our future work are given in the last section.

\section{RELATED WORKS}

\section{A. Challenges for Achieving Transparency of Cross-border and Global Food Supply Chains}

Transparency of a supply chain refers to "the extent to which all its stakeholders have a shared understanding of, and access to, the product-related information that they request, without loss, noise, delay and distortion"[63], [67]. Consumers, companies and their business parnters, government agencies, non-government organizaions are demanding more detailed information about food products with concerns over food quality, safety, social and environmental impacts. Tranparency is critical to address their concerns and to guarantee food safety, quality and provenance.

Achieving transparency of cross-border and global food supply chains is more challenging compared to that of small, local, closed and industry specific supply chains. J.H. Trienekens et al have identified key challenges in making complex, dynamic and opaque food supply chains transparent, such as differentiated and dynamic demands of consumers, government agencies and food companies for transprency information, inconsistency of governance and food quality and safety standards, inaccuracy of information exchange, infexibility and heterogeneity of supporting information systems and technologies [63], [67]. These challenges are even more to tackle for cross-border and global food supply chains: many layers of suppliers and service providers are involved; cross-border business processes are weakly linked and difficult to hamonize; cross-border regulartoy environments, trade laws and supervision mechanisms are inconsistent; high cost of politics, technology, and finance has to be paid to integrate cross-border systems and exchange transparency information [5].

Consumers' participation in current food safety supervision and management practices is not adequate and not fully motivated. R. Macfarlane argues that there is a need to better integrate consumers' interest in food safety at the international level [38]. How to use the collective intelligence of cross-border consumers to strengthen the transparency of food supply chains needs further investigation. A general framework is introduced by T. D. Ng et al for harnessing public wisdom from mass media to improve and advance existing practices to better ensure food safety [43]. The framework proposes to use social network analysis technology to distill food safety knowledge from public opinions and social discussions. G.L. Lao et al introduces a circulation management model for handling the problems in China's food safety supervision and management process. The model focuses on the reconstruction and reform of government supervision mechanism, information sharing modes and communication ways of food safety and accident information with the public [32].

\section{B. Enabling Technologies and Systems for Achieving Food Supply Chain Transparency}

Driven by increasing demands of consumers, down-stream and up-stream partners for transparency, food companies are beginning to deploy traceability system enabled by identification technologies-ranging from barcodes, RFID tags, to DNA markers-for providing tranparency information to the marketplace [10], [14], [17], [18], [21], [45], [68]. L.U. Opara has done a good review on technologies for implementing traceability system in agriculture and food supply chain: product identification technology, quality and safety measurement technology, genetic analysis technology, environmental monitoring technology, geospatial technology, software integration technology, concluding that successful implementation of traceable agricultural supply chains requires technological innovations in product identification, process and environmental characterization, information capture, analysis, storage and transmission, as well as overall system integration [45]. P.M. Wognum et al have analyzed current technical and organizational solutions and developments aiming to retrieve and provide information to consumers and decision makers concerning transparency and sustainability issues, identifying challenges to upgrade present information systems to improve transparency: information sharing and exchanging should be fostered across the whole food supply chain and network with low administrative costs and wastes, and in fair and open ways. From perspectives of food quality and safety, health, environment, ethical and privacy liberties, drawbacks and perceived benefits of four traceability information carriers - linear barcodes, RFID, tags, edible marking systems and DNA based technologies - are explored in [68] to identify factors influencing consumer's confidence in traceability technologies, and implementation priorities of such technologies in food companies.

Simulation systems, prototypes, frameworks and data models have been researched to pilot emerging technologies and standards in recent years for enhancing existing quality management system with tracking and tracing functions or 
developing new traceability systems [2], [55], [56], [71]. Based on EPCIS (EPC Information Service) standards and framework, $\mathrm{R}$. Wang et al have developed a proof-of-concept prototype to simulate processes of key food identification, data sharing within and across enterprises and tracking and tracing, in Auto-ID enabled frozen food chain [66]; M. Thakur et al introduce a new methodology for modeling and sharing food traceability information through aggregation, transition and integration of EPCIS events [63]. A service-oriented traceability system architecture and a web-based prototype implementation based on this architecture are presented to track and trace agricultural batch products along the food chain in in [56]. M.T. Wynn et al have analyzed data and process requirements in recalling product, and proposed a workflow-based coordination framework to support food manufacturers, government agencies and the general public to trace the recalled foods [71]. Implementation challenges and limitations together with advantages of using RFID in animal identification and food chain traceability control are comprehensively studied in [18], [32], [37], [57], [61], [70]. More innovative applications of this kind of Internet-of-Things technology in the life-cycle traceability of food product are expected to emerge in future around the world.

Over the past years, international organizations, academic societies, cross-border industrial associations and governments have started to work together to launch various food safety initiatives, develop numerous standards, and pilot cross-border traceability platforms to improve the transparency of global food supply chains [1], [4] , [19] , [24] , [32], [34], [35] , [55], [67] , [81] , [89] , [92]. For example, Global GAP standards, initiated by European farmers and retailers for international certification of Good Agricultural Practice and facilitating global trading, are now in the process of harmonizing similar agricultural worldwide standards (e.g. British Retail Consortium Standard, ISO 22000, International Food Standard and IFS Logistics), and re-boosting consumers' confidence through more transparency [80]. Asia-Pacific Economic Cooperation members commenced collaboration in evaluating the readiness of developing and applying traceability system in agricultural trade and production [74], [91]. Just recently, The Institute of Food Technologists launched a new Global Food Traceability Center aiming to bring together key stakeholders in global food supply chains to collaborate on food traceability [90].

From 2008 to 2012, the first two authors of this paper were involved in the research and development of over four cross-border food traceability projects, such as RFID-enabled Platform Technology for the Integrated Shenzhen-Hong Kong Food Safety and Supply Chain Management Public Information Platform, Real Time Food Quality Management Service Platform, RFID Applications in Import and Export Goods Quality Traceability and Supervision [37], [78]. From the pilot deployments of systems developed in these projects, we learned that existing traceability systems still need to be upgraded, through improved and novel functions, to empower consumers to be able to participate, both actively and easily, in the process of tracking and tracing, management, supervision and monitoring of food quality, safety and sustainability.

\section{Applications of Social Networking Technologies in Enterprises and Government Agencies}

Though in early stages, social networking technologies and mobile social applications are gaining wide adoption in enterprises and government agencies to engage with business partners, customers, prospects and the general public [6], [8], [9], [11], [13], [22], [23], [25], [28]-[30], [36], [38], [40], [41], [43], [46], [47], [49], [52], [53], [59], [69], [73], [82], [83], [92]. Gartner presents a full list of potential business applications of social software in its hype cycle report, such as social customer relationship management, social commerce, social shopping, social learning, social network payment, social business process management and social government management [40]. In China, government agencies create thousands of Weibo accounts to disseminate service information and interact with the general public [73]. Pilot study by A. Kavanaugh et al reveals that government use of social media is in the transformation: from the management of routine civil services to critical public incidents and emergencies [38].

Issues on how to use social networking technologies in different enterprise and government applications and integrate them with other emerging technologies have been investigated in the research community [6], [8]. C.J. Wu et al propose a scalable architecture for servers hosting mobile presence services (e.g. global position service) to support large-scale social network applications [69]. A web service based gateway is presented in [47] to support the integration of mobile applications with social networks. G.L. Shi et al study the applications of social network in business management from aspects of enterprise structure, industry cluster and enterprise competition capabilities [59]. Privacy and security issues are discussed in [9] to facilitate third-party applications to use private profile data and activity data in social networks in controllable ways. F. Bonchi et al provide an overview for identifying problems and challenges of using social network analysis and mining methodologies in business applications [6]. Conceptual model of enterprise application system, Social CRM System enabled by social networking and web 2.0 is given in [43]. Comprehensive surveys on mobile social networks and applications are conducted by N. Kayastha et al and N. Jabeur et al from the perspectives of application classifications, network architectures, and protocol design, privacy and trust control issues [30], [25].

In addition, social networking technologies have also aroused the attention of food industry stakeholders [20], [36], [41]. Consumers now can use general social software, like Facebook, Twitter and Sina Weibo, or specific food social applications, like FoodieQuest, and Foodspotting, to take food photos, to share favorite recipes and dishes with friends, and even to communicate food safety and quality information with government agencies [77], [78], [82], [83]. In 2010, Centers for Disease Control and Prevention of the U.S. began to use social media for food safety education [8], [36], [41], [90]. Social networking technologies played critical roles in recent large-scale recall accidents [48]. R.W. Newkirk et al qualitatively analyze the potential capability of social media in food safety and food terrorism surveillance systems, such as outbreak detection of foodborne diseases and food contamination incidents [11], [13], [52]. 
Regardless of prior works described above, a lot of researches remain to be done on how to efficiently and effectively fit social networking technologies into the context of improving transparency and visibility of supply chains, and tackle the challenges presented in part A of section II.

\section{A FRAMEWORK FOR DEVELOPING SOCIAL NETWORKS ENABLING SYSTEMS TO ENHANCE THE TRANSPARENCY AND VISIBILITY OF CROSS-BORDER FOOD SUPPLY CHAINS}

\section{A. High-Level Design of the Framework}

Due to loose, dynamic and complicated relationships within the involved stakeholders of cross-border and global food supply chains, the chains are more vulnerable to be broken; it is rather difficult to achieve full transparency and visibility of them. To maximize the advantages of employing social networks to enhance the transparency, a framework is needed to guide the development of social networks enabling traceability systems. Instead of just simply adding some social links (e.g. Facebook and Twitter gadgets) to their web sites and applications or maintaining several social accounts on popular social network platforms, the stakeholders of cross-border and global food supply chains are strongly suggested to consider: how to blend social networks into each stage of the chains; and how to align and harmonize their business processes with partners for obtaining improved transparency.

In this paper, we develop a high-level framework to fulfill above increasing needs of cross-border stakeholders in food chain. The framework presents a general architecture of a social networks-enabling food traceability system, illustrated in Fig. 1, together with three alternatives to implement the system or integrate social networks with existing food tracking and tracing solutions.

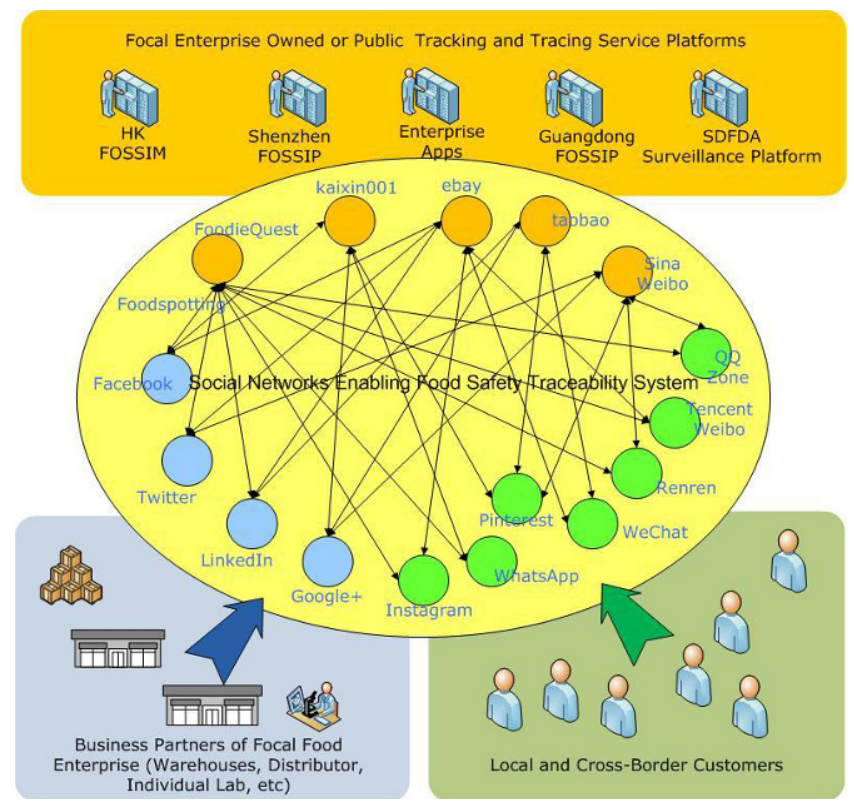

Fig. 1. A general architecture of social networks-enabling food traceability system

Basically, we recommend the stakeholders of cross-border and global supply chains to implement and deploy a social networks-enabling food traceability system according to the following guidelines:

1) The system should satisfy varieties of requirements of cross-border consumers, food companies and government agencies for food chain transparency at different levels of granularity. Inconsistent, lagged and incomplete food safety warning information on the same food disclosed by two cross-border supervision bodies usually arouses unnecessary horrors among the general public, instead of winning the confidence of the general public. Flexible coordination mechanisms and advanced algorithms should be implemented in the system to orchestrate the sharing, exchanging and disclosure of the information of food tracking, food recalls and food incidents.

2) The system needs to integrate seamlessly with such enterprise internal systems in on-demand ways, as purchasing management, warehouse management, manufacturing execution, transportation management, quality control and management, product life-cycle management, e-commerce system, sales and customer relationship management. Information of raw materials, ingredients, bill-of-materials and recipes on foods, which consumers finally select, is usually recorded in food producer's system; packaging, warehousing and shipping information is often stored in logistics service provider's system. The above information could be pulled into the social network enabling traceability system for sharing and exchanging, when the stakeholders or their friends and followers require the information, but not be able to access it easily. Comments, feedbacks, adverse food responses and even complains, posted by cross-border food consumers on different social networks, could be aggregated and pushed back to food enterprises through the system.

3) The system should be able to communicate smoothly with public-oriented supply chain management platforms run by third party, and food safety supervision and monitoring systems operated by cross-border government agencies. Quality information, food recall alerts, import and export inspection quarantine information, which are normally resided in systems located in one side of the country or region border, are difficult to be accessed by consumers and companies in the other side. The system can act as a bridge to strengthen the easy-to-be-broken cross-border and global food supply chains. We plan to integrate the prototype $O S C M-F D$, which we are developing, with FOSSIP (Food Safety and Supply Chain Information Platform) and FOSSIM (Food Safety and Supply Chain Information Management System/Portal) developed in the projects mentioned in part B of section II, and other provincial and national food safety supervision systems.

4) The system should be capable of managing, aggregating and analyzing the information dispersed in various social network accounts owned by different food chain stakeholders, from the perspectives of food supply chain management, and with the purposes of food tracking and 
tracking, food chain transparency and visibility. Nowadays most consumers, food companies and government agencies own or operate more than one social network accounts; these accounts are usually hosted on different social network platforms, and are manipulated in loose, inefficient, separate and even disorder ways. For example, one cross-border food company we know well is running five social network accounts - two on Sina Weibo, one each on Tencent Weibo, Facebook and Twitter-for doing marketing campaign. The company's corresponding governmental supervision and monitoring agencies in the Mainland China and Hong Kong have separate accounts on these platforms to handle complaints from the general public. The company's customers and business partners also use their preferred social networks to communicate with friends, government agencies and the company. Different from some existing early warning systems, which just crawls information from social networks to detect food incidents, the social networks-enabling food traceability system should become a critical enablement for coordinating and aligning the business processes of the company's cross-border food supply chain.

5) Besides, the system should leveraging emerging technologies of product identification, software architecture and application integration to reuse existing systems deployed at food companies and governments, instead of reinventing all the wheels.

\section{B. Implementation Alternatives}

In consideration of different maturity level of information technology applications in food companies and government agencies, and the differences of mechanisms of hosting third-party applications between various social network platforms, three main alternatives to implement and deploy a social networks-enabling food traceability system are identified in our study as the following:

1) Enterprise Applications Centered Model — developing a social networks-based traceability system centering on enterprise applications. This alternative suits for the companies and government agencies, which have relatively complete and mature internal enterprise systems and have already started piloting social networking applications to extend the collaboration, cooperation and interaction functions of their existing systems. For instance, a food company can customize and add social network enabled tracking and tracking functions in the customer and supplier relationship modules of its ERP system, in its CRM system, or in its enterprise portal system; a government agency can link its social network communities with its food surveillance system or food safety early warning system; traceability functions of a third party food safety and quality service platform, like FOSSIP and FOSSIM, can also be enhanced by adding social networking capabilities.

This implementation method makes it easier for the stakeholders in cross-border food supply chains to benefit quickly from social networks, with less integration efforts while still focusing on their former business processes. However, the method will require them to invest more energy and resources in tailor-making special software modules and modifying their existing systems to manage different types of social network accounts, and to learn how to utilize advanced social network analysis techniques.

2) Traceability Applications Hosted on Social Network Platforms - developing and deploying a social networks-based traceability system as a third-party application running on existing social network platforms. Current popular social network platforms, like Twitter, Facebook, Sina Weibo and Tencent Weibo, have provided various flexible mechanisms to host third-party game and music applications, such as in-container apps, Wei Connect, frame apps, browser plug-ins and mobile social gadgets. These platforms seek to supply their users with new and attractive contents through third-party applications to increase the staying-on-site time. Third-party applications can leverage the big user bases and connections, already built in the social network platforms, to attract new users to the business and entertainment services they support. Another advantage of hosting the food traceability system on social network platforms lies in that: food firms and government agencies have lower entry barrier to developing, deploying and maintaining the system in terms of finance and time cost - since vendors of social network platforms have already established reliable hardware and software infrasctucture, food firms and government agencies don't need to repeat investment for those facilities, but to pay according to their real usage; developers have developed various SDKs for different operating systems, software library packages in multiple programming lanugages, sample applications and testing toolkits for developing third-party applications, which enable food firms and government agencies to be able to find inexpensive and capable developers and service providers.

Disadvantages of implementing the food traceability system by this alternative comprise: technologies for integrating third-party social applications with enterprise and government legacy systems, along with privacy control and data security issues, has not been thoroughly studied yet; there lacks easy-to-use tools and middleware in current market; aggregating, filtering and analyzing information available on other proprietary social network platforms, and fusing the results into the context of food traceability appears not an easy job, though not impossible.

3) Independent Social Networks Driven Traceability System-developing and deploying a traceability system outside of enterprise applications and current social network platforms. The system can be deployed using traditional client-server framework or operate on platform-as-a-service cloud platforms. The system itself even can be implemented with social networking platform technologies, such as Apache Shindig, to host other 
innovative social apps. As discussed in section II, the transparency of cross-border and global food supply chains is determined by the levels of the degree, to which the business processes of each food stakeholder are aligned and orchestrated and the heterogeneous systems are integrated, for exchanging and sharing tracking and tracing information. This implementation alternative has the potential to improve and drive the transparency and visibility of cross-border and global supply chains to unprecedented levels. Stakeholders in the chains could adapt flexible strategies and techniques to embed different business contexts into the system. It provides them with an open, transparent, dynamic and flexible environment to work cooperatively and collectively with each other for achieving the ideal transparency. For example, loosely connected food firms are able to quickly build temporary relationships with business partners and government agencies only because of the recall of one single batch of food; consumers are able to acquire complete food safety and quality information from both local and abroad friends with the social apps they favor best; government agencies can refer to the early warning information of food incidents issued by their crossing border counterparties to make timely decision for inspecting import foods and publishing warning messages; all discourses happening outside of enterprise applications and current social network platforms can be captured, transformed, and linked together with least information loss for obtaining clues of food incidents.

This implementation alternative is able to surpass the limitations of Enterprise Applications Centered Model in the sense that the mechanisms for collaboration and cooperation in the model are usually confined to the applications themselves. Obvious advantages of the alternative over Traceability Applications Hosted on Social Network Platform include: the independent system is able to integrate with any enterprise and government applications and third-party service platforms using numerous integration technologies; the independent system is able to collect, aggregate and analyze comments and communication information of participants from any social network accounts, once whose owners allow the system to access; the independent system is capable of strengthening the weak links of cross-border and global supply chains, reconstructing or mending the broken ones for coming up a complete and clear view of the supply chain networks.

Currently, most food companies and government agencies have just started launching social application initiatives. They can use the first two implementation alternatives to prove concepts for improving the transparency and visibility of partial supply chain stages. Focal enterprises in cross-border and global supply chains, such as big food producers or retailers, leading enterprises and government agencies with high motivation and capabilities of using social networks in business and public crisis management are encouraged to employ the third alternative to implement a novel food safety traceability system.

No matter which alternatives do the stakeholders in cross border and food chains select to develop and deploy a social networks-enabling food traceability system, they need to think carefully about how to leverage and utilize such common technologies as: a) social application programming interfaces, e.g. proprietary APIs from Facebook and open cross-platform APIs from Google along with a few of other social network platform operators; b) social plugins, e.g. Facebook's 'like' button and 'share' dialog, Twitter's 'Tweet' and 'Follow' button; c) social web analytics and mining technology-a number of processing and analysis techniques for capturing, cleansing, filtering, measuring, analyzing and interpreting volume of social information, and advanced algorithms for clique detection, network analysis, channel analysis, complex and exceptional event analysis, sentimental analysis; d) interactive data visualization technology, software tools and libraries, e.g. Graphviz, NetworkX, NetMiner; e) product identification technologies, e.g. barcode, RFID, DNA fingerprint; $f$ ) digital identity authentication technology, like OpenID and OAuth; $g$ ) software architecture, framework, data management and integration technologies, e.g. service-oriented architecture, MapReduce, Model-View-Controller design patterns, web services, Hadoop, business process execution and modeling language, REST; $h$ ) last but not the least, location based services, mobile applications and cloud computing technologies.

\section{PROTOTYPE ARCHITECTURE OF A SOCIAL NETWORKS ENABLING TRACEABILITY SYSTEM FOR GUANGDONG-HONG KONG CROSS-BORDER FOOD SUPPLY CHAINS}

\section{A. Prototype Architecture of OSCM-FD}

A prototype, titled $O S C M-F D$, based on the proposed framework, is being developed in our work. Fig. 2 presents the architecture of $O S C M-F D$, which consists of six major function modules:

1) Social Community Manager - a management component supporting consumers, food companies and government agencies to manage social accounts and communities they have created on different social network platforms. $O S C M-F D$ is supposed to to integrate with four platforms: Sina Weibo, Tencent Weibo, Facebook and Twitter. Using this component, end users of OSCM-FD can manage more than one different social network accounts hosted on one single platform or several platforms: add and delete account; update personal profile information; set privileges and rules for accessing sensitive and privacy information; and maintain list of followers and friends.

2) Social Information Publisher-an information disseminating hub facilitating users to publish, update, delete, reply and synchronize text messages, photos, and videos on the foods they consume, across different social network accounts. With this component, food enterprises 
and government agencies are able to response to the comments and complaints of consumers, to distribute food safety warning information, and to recall contaminated foods through one single portal, rather than performing these activities repeatedly through each individual account on different social platforms. For consumers who are concerned about the safety and quality of the food they eat, they can use this component to submit adverse response, to browse feedbacks and comments from other consumers, or even to solicit advice and recommendations of their friends and food specialists.

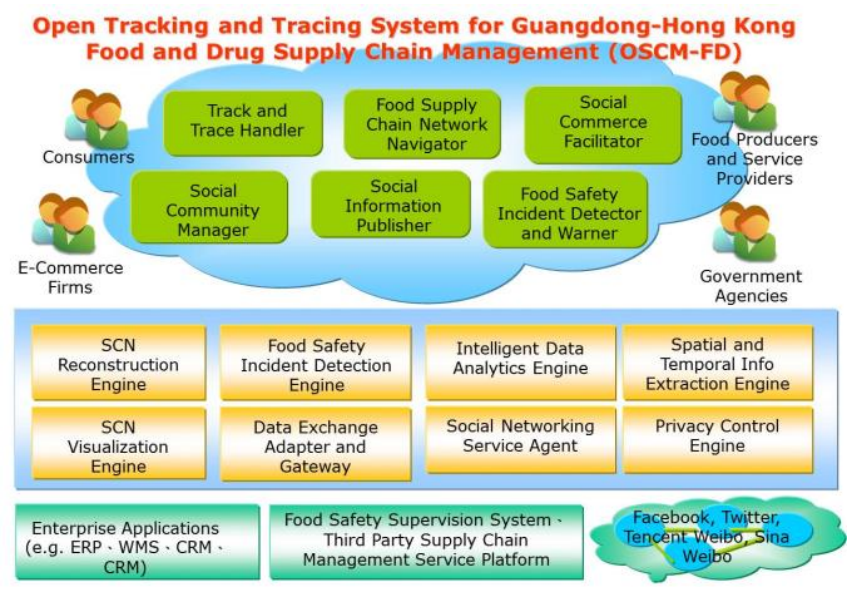

Fig. 2. Functional architecture of $O S C M-F D$.

3) Food Supply Chain Network Navigator - a visualization component directing the stakeholders in food chains to work collaboratively for tracking and tracing the cross-border foods. Structures of cross-border and global supply chains are usually multi-echelon supply networks bearing great uncertainties and dynamics. The component enables the stakeholders to participate in the construction or reconstruction of cross-border and global supply chains, in loose but efficient and effective ways. They can interact with each other and contribute complimentary transparency and visibility information once cross-border and global supply chains are broken or the tracking and tracing information are lost.

4) Food Safety Incidents Detector and Warner-an indispensable component of any food traceability solutions. Different from the traditional food safety early-warning system operated by government agencies, and the social web crawler for the purposes of sentimental analysis and infection disease detection, and aggregated query data based trends analysis system (e.g. Google Flu Trends Estimates), this component integrates the business processes of food firms managing their internal operations and external collaborations with their partners along the supply chain, and the processes of government agencies inspecting, supervising and monitoring food quality and safety. Advanced techniques such as data cleansing, multi-dimensional analysis, process mining, web mining and social mining are employed to filter out the fraud social information, to detect and predict food incidents patterns, and to facilitate users to drill-down to the details or roll-up to a quick overview of the detected incidents. Moreover, the component leverages knowledge bases of government authoritative agencies to verify the accuracy and authenticity of the doubtful food safety incidents through similarity matching with former cases.

5) Social Commerce Facilitator-a trial value-added component making cross-border online food shopping easier and more reliable. Oversea online shopping has prospered on an unimaginable scale in recent years [84]. Consumers in America, Europe, Russia and Hong Kong can purchase quality clothes, suitcases, mobile phones, shoes and foods from the Mainland China via internet; young parents in China have started to buy baby formulas, baby drinks and other baby foods from overseas. However, quality and safety is still the biggest concern when consumers buy foods online. The component becomes a convenient, low-cost, efficient and effective pipeline - through which cross-border online food consumers are able to communicate with food firms for acquiring food quality and traceability information, publishing feedbacks and comments; food firms can launch and improve marketing campaigns and promotions, test new food product ideas, and lead prospects to make new buying decisions.

6) Track and Trace Handler - a unified interface or mobile applications for users to directly query the tracking and tracing information of foods by scanning the barcodes or RFID tags attached to them with smart mobile devices. Aggregated and cleansed traceability information is pushed to food consumers in real time once they demand it.

Corresponding to above six modules, such software components as Supply Chain Network (SCN) Reconstruction Engine, SCN Visualization Engine, Food Safety Incidents Detection Engine, Data Exchange Gateway, Data Exchange Adapter, Intelligent Data Analytics Engine, Social Networks Service Agent, Spatial and Temporal Information Extraction Engine and Privacy Control Engine are implemented on the server side or middle layer of $O S C M-F D$. We will discuss the details of these components in our future work, and omit them here due to the length limitation of this paper.

\section{B. Use Scenarios for Piloting the Prototype System}

We have approached representative stakeholders in Guangdong-Hong Kong cross-border food supply chains to pilot the being-developed prototype. Here are the major use scenarios in four pilots we are going to conduct:

1) The first pilot will be conducted at a food manufacturer in China, which has lots of worldwide business partners and consumers. This pilot mainly aims to test the functions of Social Networks Service Agent, Food Supply Chain Network Navigator, Social Information Publisher, Data Exchange Adapter and Data Exchange Gateway. The pilot is to integrate OSCM-FD with the company's ERP, WMS, $\mathrm{SCM}$ and CRM. The company will use OSCM-FD to 
manage its four social network accounts on Tencent Weibo and Sina Weibo, responding to consumers' feedback and complaints, demonstrating tracking and tracing information of foods, and showing foods supply chain networks together with bill-of-materials information. Business partners of the company, such as suppliers, logistics providers, distributors and retailers are also encouraged to trial-run $O S C M-F D$ to prove its capabilities in aligning and harmonizing business processes of cross-border and global food supply chain management of different stakeholders.

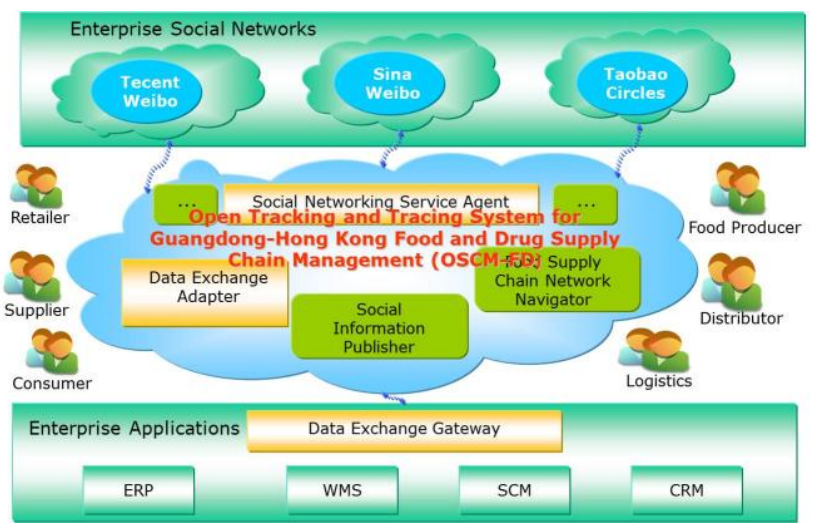

Fig. 3. $O S C M-F D$ pilot at a food manufacturer in China.

2) The second pilot is to be conducted at government agencies for inspecting and monitoring food quality and safety of import and export foods. At least one government agency on each side of the border crossing the Mainland China and Hong Kong is supposed to use OSCM-FD to manage their social network accounts operating separately on Tencent Weibo, Sina Weibo, Facebook and Twitter. Objectives of this pilot include: testing the capabilities of Data Exchange Adapter and Data Exchange Gateway in integrating $O S C M-F D$ with government inspection and supervision systems and third-party service platforms for tracking and tracking food quality and safety; investigating the potentials and mechanisms of bilateral government agencies collaboration through social networks; exploring innovative ways for improving the surveillance efficiency and responding rate of government agency on one border side in dealing with the feedbacks and complaints from the other side consumers.

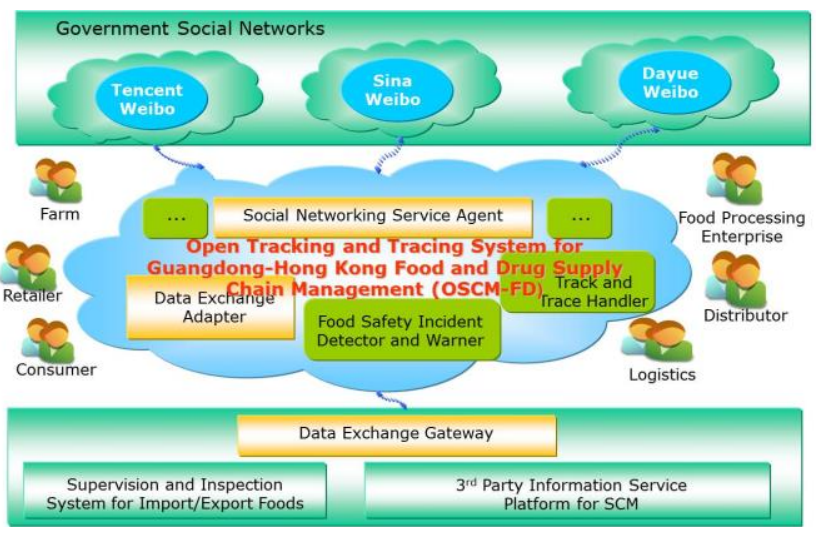

3) Capabilities of OSCM-FD in satisfying the requirements of cross-border consumers for safety and transparency of food chains will be examined in the third pilot. This pilot focuses on the study of how consumers interact and work collectively through $O S C M-F D$ to repair the cross-border food supply chains, supplementing each other to acquire accurate, complete and timely food quality and safety information. Active and massive participation can drive government agencies to adopt more open and transparent means in managing food safety crises and incidents, recalling foods and disclosing early warning information.

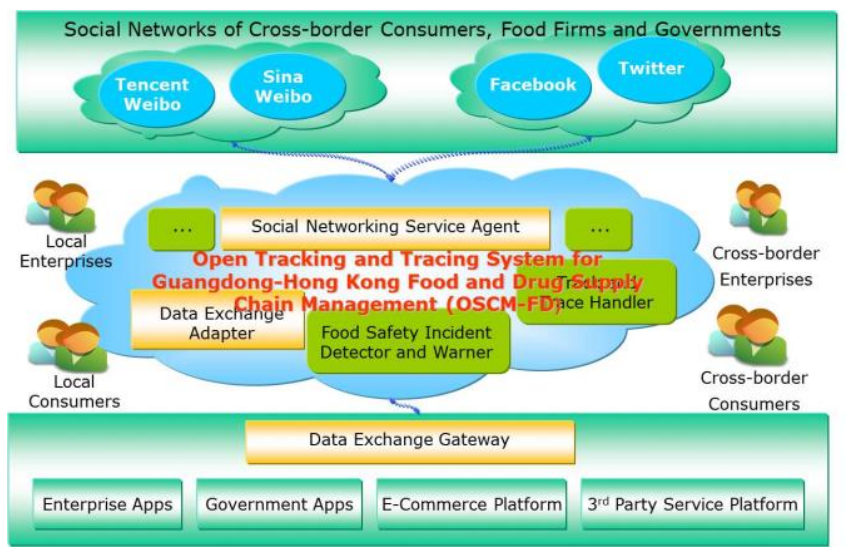

Fig. 5. OSCM-FD pilot within cross-border consumers.

4) Finally, a trial run of $O S C M-F D$ is to be done at a start-up food e-commerce company with online-to-offline business. This company establishes a web site for consumers to select fresh vegetables, fruits, cooking oils, canned foods, processed foods and drinks. Consumers are able to finish both order placement and payment on the same website. The company differentiates its business from the competitors in the ways that its consumers are able to get the tracking and tracking information of the foods they buy online and offline; the company opens a few of offline convenience stores near Shenzhen-Hong Kong border crossings for cross-border consumers to pick up foods they order online; the company operates several Tencent Weibo and Sina Weibo accounts for attracting prospects to its website and offline stores. The company is to employ $O S C M-F D$ to evaluate their innovative social commerce model, and seek to develop new ways to improve service levels and expand cross-border market share.

Fig. 4. $O S C M-F D$ pilot at government agencies. 


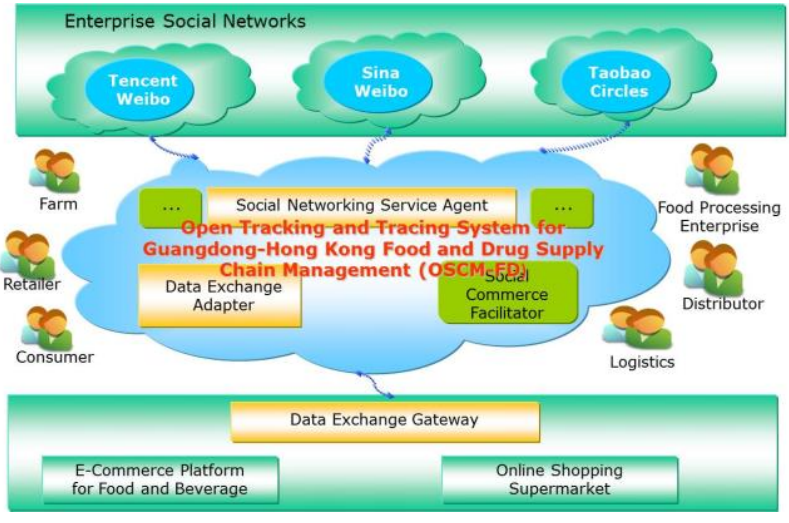

Fig. 6. $O S C M-F D$ pilot at a food e-commerce company.

\section{CONCLUSION AND FUTURE WORK}

Consumers in both emerging economies and advanced countries are increasingly demanding safe, high-quality and healthy foods; they are purchasing vegetables, drinks and processed foods in global markets through online stores or offline retailers. Food safety incidents and scandals constantly breaking out worldwide are significantly reducing consumers' trust in global foods. Transparency and visibility of cross-border and global food chains are critical to ensure the safety and quality of global foods, and to rebuild consumers' confidence, but it is difficult to achieve due to the diversities of consumers' demands, raw materials and ingredients, the loose and dynamic relationships between food firms and government agencies, the technology and resource barriers in aligning business processes, exchanging and sharing information, and the frequently changing government regulations and standards.

Social networking technologies and social applications are promising enablers to enhance the transparency and visibility of cross-border and global food supply chains. With these technologies, stakeholders in the chains are able to work collaboratively and collectively in participating in open discussion, giving comments and feedbacks on the safety and quality of the foods they are concerned about, reporting adverse food responses and sharing early warning messages. To study how to utilize social networking technologies and social applications in the context of tracking and tracking global foods, we propose a framework for developing social networks enabling food traceability systems in this paper. The framework presents architecture guidelines and technology alternatives for implementing a social networks-enabling food traceability system. A prototype, titled $O S C M-F D$, is being developed according to the framework. Architecture and functions of six modules of $O S C M-F D$ are also discussed in this work, as well as the use scenarios for piloting the prototype system at four different types of food stakeholders.

This research and the proposed framework are motivated directly by the requirements of food firms, government agencies inspecting the quality and safety of import and export foods, and cross-border consumers, when we pilot the Internet-of-Things based food safety tracking and tracking platforms developed in our several R\&D projects. In the future, we will continue to investigate the issues of using social networking technologies and the proposed framework for developing food traceability applications, such as relationship based mechanisms and implementation methods for accessing and sharing private data and sensitive social data, technolgoies for integrating enterprise and government legacy systems with social networking applications, and advanced algorithms for mending broken global supply chains with the support of social graphs or the hidden topological relationship patterns. Validity and efficiency of the proposed framework will be analyzed further after we finish the development of OSCM-FD system and the first round pilots of the system.

\section{REFERENCES}

[1] D. Abler, "Demand growth in developing countries," OECD Food, Agriculture and Fisheries Papers, No. 29, OECD Publishing, 2010.

[2] A. Bechini, M.G.C.A. Cimino, B. Lazzerini, F. Marcelloni, and A. Tomasi, "A general framework for food traceability," The 2005 Symposium on Applications and the Internet Workshops, Saint Workshops, pp.366-369, 2005.

[3] A.J.M. Beulens, D.F. Broens, P. Folstar, and G.J. Hofstede, "Food safety and transparency in food chains and networks relationships and challenges," Food Control, Vol.16(6), pp.481-486, July 2005.

[4] T. Bhatt, C.Hickey, and J. McEntire, "Pilot projects for improving product tracing along the food supply system - final report," Institute of Food Technologists, $2012 . \quad$ Available: http://www.fda.gov/downloads/Food/GuidanceRegulation/UCM341810. pdf

[5] G. Blissett and J.C. Harreld, "Full value traceability-a strategic imperative for consumer product companies to empower and protect their brands," IBM Institute for Business Value, IBM Global Business Services, 2008.

[6] F. Bonchi, C. Castillo, A. Gionis, and A. Jaimes, "Social network analysis and mining for business applications," ACM Transactions on Intelligent Systems and Technology, Vol.2 (3), Article 22, May 2011.

[7] D. Brady, "The organic myth," Bloomberg Business Week Magazine, October, 2006. Available: http://www.businessweek.com/stories/2006-10-15/the-organic-myth

[8] B. Chapman, "I updated my Facebook status update to 'I just got food poisoning,", presented at 2010 Food Safety Education Conference, Atlanta, Georgia, March 24, 2010.

[9] Y. Cheng, J. Park, and R. Sandhu, "Preserving user privacy from third-party applications in online social networks," in Proceedings of the 22nd International Conference on World Wide Web Companion (WWW '13 Companion). International World Wide Web Conferences Steering Committee, Republic and Canton of Geneva, Switzerland, pp.723-728, 2013.

[10] P. Chrysochou, G. Chryssochoidis, and O. Kehagia, "Traceability information carriers - the technology backgrounds and consumers' perceptions of the technological solutions," Appetite, vol.53 (3), pp.322-331, December 2009.

[11] N.A. Christakis and J.H. Fowler, "Social network sensors for early detection of contagious outbreaks," PLoS ONE Vol.5 (9), e12948, September 2010.

[12] P. Conroy, "2011 Consumer food and product insights survey: whose responsibility is it to communicate product recall information?" Deloitte LLP. Available: www.deloitte.com/us/foodsafety/2011survey.

[13] C.D. Corley, D.J. Cook, A.R. Mikler, and K.P. Singh, "Text and structural data mining of influenza mentions in web and social media,", International Journal of Environmental Research and Public Health, Vol.7, pp.596-615, February 2010.

[14] F. Dabbenea and P. Gay, "Food traceability systems: performance evaluation and optimization," Computers and Electronics in Agriculture, Vol.75 (1), pp.139-146, January 2011.

[15] A. Dubrawski, P. Sarkar, and L.J. Chen, "Trade-offs between agility and reliability of predictions in dynamic social networks used to model risk of microbial contamination of food," in the Proceedings of the 2009 International Conference on Advances in Social Network Analysis and Mining (ASONAM '09). IEEE Computer Society, Washington, DC, USA, pp.125-130, 2009. 
[16] M. Fritz and G. Schiefer, "Tracking, tracing, and business process interests in food commodities: A multi-level decision complexity," International Journal of Production Economics, vol.117 (2), pp.317-329, February 2009.

[17] H.K. Froschle, U. Gonzales-Barron, K. McDonnell, and S.Ward, "Investigation of the potential use of e-tracking and tracing of poultry using linear and 2D barcodes," Computers and Electronics in Agriculture, vol.66 (2), pp.126-132, 2009.

[18] L.R. Garcia and L. Lunade, "The role of RFID in agriculture: Applications, limitations and challenges," Computers and Electronics in Agriculture, vol.79 (1), pp.42-50, October 2011.

[19] M.A. Hamburg, "Food safety modernization act: putting the focus on prevention," News and Features, January 2011. Available: http://www.foodsafety.gov/news/fsma.html.

[20] M. Helander, "Food safety in a global supply chain," presented at Isenberg School of Management, UMass Amherst Campus, Fall 2009 Operations Research/Management Science Seminar Series, September, 2009.

[21] I.H. Hong, J.F. Dang, Y.H. Tsai, C.S. Liu, W.T. Lee, M.L. Wang, and P.C. Chen, "An RFID application in the food supply chain: A case study of convenience stores in Taiwan," Journal of Food Engineering, vol.106 (2), pp.119-126, September 2011.

[22] B. Hollerit, M. Kroll, and M. Strohmaier, "Towards linking buyers and sellers: detecting commercial intent on twitter," in the Proceedings of the 22nd international Conference on World Wide Web Companion (WWW '13 Companion). International World Wide Web Conferences Steering Committee, Republic and Canton of Geneva, Switzerland, pp. 629- 632, 2013.

[23] P. Hu, J. Li, and W.C. Lau. 2013, "PIXS: programmable intelligence for cross-platform socialization," in the Proceedings of the 5th ACM workshop on HotPlanet (HotPlanet '13). ACM, New York, NY, USA, pp.33-38, 2013.

[24] B.M. Inerney, G. Corkery, G. Ayalew, S. Ward, K. Mc Donnell, "A preliminary in vivo study on the potential application of a novel method of e-tracking in the poultry food chain and its potential impact on animal welfare," Computers and Electronics in Agriculture, vol. 79(1), pp.51-62, October 2011.

[25] N. Jabeur, S. Zeadally, and B. Sayed, "Mobile social networking applications," Communications of the ACM, vol.56 (3), pp.71-79, March 2013.

[26] M. Jones, "It pays to be transparent," Asia Food Journal, pp.26-27, March-April 2010.

[27] Y.S. Kang and Y.H. Lee, "Development of generic RFID traceability services," Computers in Industry, vol.64 (5), pp.609-623, 2013.

[28] A. Kavanaugh, E.A. Fox, S. Sheetz, S. Yang, L.T. Li, T. Whalen, D. Shoemaker, P. Natsev, and L.X. Xie, "Social media use by government: from the routine to the critical," in the Proceedings of the 12th Annual International Digital Government Research Conference: Digital Government Innovation in Challenging Times (dg.o '11). ACM, New York, NY, USA, pp. 121-130, 2011.

[29] M. Kim, D. Newth, and P. Christen, "Modeling direct and indirect influence across heterogeneous social networks," in the Proceedings of the 7th Workshop on Social Network Mining and Analysis (SNAKDD '13) ACM, New York, USA, Article 9, 2013.

[30] N. Kayastha, D. Niyato, P. Wang, and E. Hossain, "Applications, architectures, and protocol design issues for mobile social networks: a survey," in the Proceeding of the IEEE, vol. 99 (12), pp. 2130-2158, December 2011.

[31] L. Kremers, "The right fit," Asia Food Journal, pp.9-10, July-August 2010.

[32] G.L. Lao and Q.Y. Wang, "A circulation management model for safer food supply based on RFID," in the Proceedings of 4th International Conference on Wireless Communications, Networking and Mobile Computing (WiCOM '08), pp.1-4, 2008.

[33] R. Li, "Handling recipe changes," Asia Food Journal, pp.7-8, July-August 2010.

[34] Y. Li, M.R. Kramer, A.J.M. Beulens, and J.G.A.J. van der Vorst, “A framework for early warning and proactive control systems in food supply chain networks," Computers in Industry, vol.61 (9), pp.852-862, 2010.

[35] P.A Liao, H.H. Chang, and C.Y. Chang, "Why is the food traceability system unsuccessful in Taiwan? Empirical evidence from a national survey of fruit and vegetable farmers," Food Policy, vol.36 (5), pp.686-693, October 2011.

[36] J. Liu, "Food safety information management in the age of twitter," presented at 2010 Food Safety Education Conference, Atlanta, Georgia, March 24, 2010.

[37] S.L. Liu (editor), Application of RFID Technology in traceability and risk warning for food safety (in Chinese), Science Press, China, March 2012

[38] Y.B. Liu, Y.X. Zhou, and G. Liu, "Chinese government use of social media: a case of Shanghai Weibo @Shanghaicity," in the Proceedings of 6th IEEE International Conference on Digital Ecosystems Technologies, Campione, Italy, June 2012.

[39] R. Macfarlane, "Integrating the consumer interest in food safety: the role of science and other factors," Food Policy, vol.27 (1), pp.65-80, February 2002

[40] J. Mann, "Hype cycle for social software, 2013," Gartner Research Report, July 2013.

[41] M.J. Marosits, "Using social media for food safety education," presented at 2010 Food Safety Education Conference, Atlanta, Georgia, March 24, 2010.

[42] M.Y. Miao, X. Liu, Y.Q. Duan, R.M. Wang, and Z. Fu, "Critical success factors for implementing traceability systems in Chinese food enterprises," in the Proceeding of the International Conference on Management and Service Science (MASS), Wuhan, China, August 2011.

[43] S. Mohan, E. Choi, and D. Min, "Conceptual modeling of enterprise application system using social networking and web 2.0 'social CRM system'," in the Proceedings of International Conference on Convergence and Hybrid Information Technology, pp.237-244, 2008.

[44] T.D. Ng and C.C. Yang, "A framework for harnessing public wisdom to ensure food safety," in the Proceedings of IEEE International Conference on Intelligence and Security Informatics, (ISI '09), pp.185-187, 2009.

[45] L.U. Opara, "Traceability in agriculture and food supply chain: a review of basic concepts, technological implications, and future prospect," Journal: Food, Agriculture and Environment, vol.1 (1), pp.101-106, 2003.

[46] G. Papadakis, K. Tserpes, E. Sardis, M. Kardara, A. Papaoikonomou, and F. Aisopos, "Social media meta-API: leveraging the content of social networks," in the Proceedings of the 21st international Conference Companion on World Wide Web (WWW'12 Companion). ACM, New York, NY, USA, pp.271-274, 2012.

[47] V. Pantoja and M. Endler, "A web service for flexible integration of mobile applications with social networks," in the Proceedings of $3 \mathrm{rd}$ International Workshop on Middleware for Pervasive Mobile and Embedded Computing (M-MPAC '11), New York, USA, Article 4, pp.1-7, 2011

[48] J. Payne, "Preparing for the perfect storm in food safety", 2010, Online article available at: http://www.foodmanufacturing.com/articles/2010/01/preparing-perfectstorm-food-safety

[49] A. Platt and C. Hood, "Understanding user's needs in information gathering in social networks," in the Proceedings of the 3rd international workshop on Modeling social media (MSM '12). ACM, New York, NY, USA, 9-12, 2012.

[50] A.H.M. Shamsuzzoha, M. Ehrs, R. Addo-Tenkorang, D. Nguyen, Duy, and P.T. Helo, "Performance evaluation of tracking and tracing for logistics operations," International Journal of Shipping and Transport Logistics, vol. 5 (1), pp31-54, November 2013.

[51] S. New, "The transparent supply chain," Harvard Business Review, vol.88 (10), pp.76-81, October 2010

[52] R.W. Newkirk, J.B. Bender, and C.W.Hedberg, "The potential capability of social media as a component of food safety and food terrorism surveillance systems," Foodborne Pathogens and Disease, vol.9 (2), 2012.

[53] C. ONeil, "Food safety messages in the media: from recalls to recipes," presented at 2010 Food Safety Education Conference, Atlanta, Georgia, March 24, 2010.

[54] K. Prouty, "Food safety and traceability 2011", Research Report, Aberdeen Group, 2011.

[55] A. Regattieri, M. Gamberi, and R. Manzini, "Traceability of food products: general framework and experimental evidence," Journal of Food Engineering, vol.81 (2), pp.347-356, July 2007. 
[56] L. Ruiz-Garciaa, G. Steinberger, and M. Rothmund, "A model and prototype implementation for tracking and tracing agricultural batch products along the food chain," Food Control, vol.21 (2), pp.112-121, February 2010.

[57] T.C. Schroeder and G.T. Tonsor, "International cattle ID and traceability: competitive implications for the US," Food Policy, vol.37 (1), pp.31-40, February 2012.

[58] R. Setola and M.C. De Maggio, "Security of the food supply chain," in the Proceedings of 31st Annual International Conference of the IEEE EMBS, Minneapolis, Minnesota, USA, pp. 7061-7064, September 2009.

[59] G.L. Shi and W. Xu, "Advances in applications of social network in business management," in the Proceedings of International Conference on Web Information Systems and Mining, Sanya, China, vol. 1, pp.79-83, 2010.

[60] Y. Sheffi, "Building a resilient supply chain," Harvard Business Review, vol.1 (8), pp.1-4, October 2005.

[61] J. Shi, Y.J. Li, W. He, and D. Sim, "SecTTS: a secure track \& trace system for RFID-enabled supply chains," Computers in Industry, vol.63 (6), pp.574-585, August 2012.

[62] A. Tai, "Traceability from field to fork," Asia Food Journal, pp.11-12, July-August 2010.

[63] M. Thakur, C.F. Sorensen, F.O. Bjornson, E. Foras, and C.R. Hurburgh, "Managing food traceability information using EPCIS framework," Journal of Food Engineering, vol.103 (4), pp.417-433, April 2011.

[64] J.H. Trienekens, P.M. Wognum, A.J.M. Beulens, and J.G.A.J. van der Vorst, "Transparency in complex dynamic food supply chains," Advanced Engineering Informatics, vol. 26, No. 1, pp. 55-65, January 2012.

[65] P. Tsiakis, N. Shah, and C.C. Pantelides, "Design of multi-echelon supply chain networks under demand uncertainty," Industrial and Engineering Chemistry Research, vol.40 (16), pp.3585-3604, 2001.

[66] R. Wang, S. Prives, R. Fischer, M. Salfer, and W.A. Gunthner, "Data analysis and simulation of Auto-ID enabled food supply chains based on EPCIS standard," in the Proceeding of the 2011 IEEE International Conference on Automation and Logistics (ICAL), pp.58-63, Chongqin, China, August 2011.

[67] X. Wang, D. Li, and C. OBrien, "Optimisation of traceability and operations planning: an integrated model for perishable food production," International Journal of Production Research, vol.47 (11), pp.2865-2886, June 2009.

[68] P. M. Wognum, H. Bremmers, J.H. Trienekens, J.G.A.J. van der Vorst, and J. M. Bloemhof, "Systems for sustainability and transparency of food supply chains - current status and challenges," Advanced Engineering Informatics, Vol. 25, No.1, pp. 65-76, January 2011.

[69] C.J. Wu, J.M. Ho, and Ming-Syan Chen, "A scalable server architecture for mobile presence services in social network applications," IEEE Transactions on Mobile Computing, vol. 12 (2), pp. 386-398, Feb. 2013.

[70] Y.B. Wu, D.C. Ranasinghe, Q.Z. Sheng, S. Zeadally, and J. Yu, "RFID enabled traceability networks: a survey," Distributed and Parallel Databases, vol. 29 (5-6), pp.397-443, 2011.

[71] M.T. Wynn, C. Ouyang, A.H.M. ter Hofstede, and C.J. Fidge, "Data and process requirements for product recall coordination," Computers in Industry, vol.62 (7), pp.776-786, September 2011.

[72] R.M.W. Yeung and W.M.S. Yee, "A profile of the mainland Chinese cross-border shoppers: cluster and discriminant analysis," Tourism Management Perspectives, vol.4, pp.106-112, 2012.

[73] 2012 Report on Government Use of Sina Weibo, 2012. Available: http://yuqing.people.com.cn.

[74] APEC Food Safety Cooperation Forum Operating Principles, APEC Food Safety Cooperation Forum, 2011. Available: http://www.apec.org.

[75] Emergency Prevention System (EMPRES) for Food Safety Strategic Plan, Food and Agriculture Organization of the United Nations, 2010. Available: http://www.fao.org/docrep/012/i1646e/i1646e.pdf.

[76] FoodieQuest Website: http://playfoodiequest.com/.

[77] Foodspotting Website: http://www.foodspotting.com.

[78] Food Safety Information Platform. Website: http://www.lscm.hk/eng/channel.php?channel=licensing-opportunities\#f ood-safety-information-platform

[79] Frequently Asked Questions on Food Supply of Hong Kong. Available: http://www.fhb.gov.hk/en/press and publications/otherinfo/index.html.

[80] Global Good Agricultural Practice. Available: http://www.globalgap.org
[81] Handbook for Introduction of Food Traceability Systems, Food Marketing Research and Information Center (FMRIC) 2008. Available: http://www.fmric.or.jp/trace/en/

[82] iResearch China Commercialization of Weibo Report 2012, iResearch Consulting Group, 2012.

[83] iResearch China Social Network Market Research 2010-2011, iResearch Consulting Group, 2012.

[84] Modern Spice Route - the Cultural Impact and Economic Opportunity of Cross-Border Shopping, PayPal research report, 2013. Available: http://www.paypal.com/spiceroutes.

[85] Online article, "FMI grocery shopper trends 2011 consumers more confident in safety of food supply," 2011. Available: http://www.fmi.org/news-room/latest-news/view/2011/05/10/fmi-grocer y-shopper-trends-2011 consumers-more-confident-in-safety-of-food-sup ply.

[86] Online news, "Food safety incidents review in recent years" 2011. Available:

http://english.cntv.cn/program/china24/20110421/113309.shtml.

[87] Online news, "Chinese Premier calls for more efforts to heed public opinion"2011. Available: http://news.xinhuanet.com/english2010/china/2011-04/17/c 13833215. htm.

[88] Online news, "FMI consumer trends 2007: confidence in food safety down, energy costs changing how people shop," May 2007. Available: http://www.fmi.org/news-room/latest-news/view/2007/05/07/

[89] Pathway to Global Product Safety and Quality -A Special Report, U.S. Food and Drug Administration, July 2011

[90] Press release, "IFT launches Global Food Traceability Center ," July 17, 2013. Available: http://www.ift.org/food-technology/daily-news/2013/july/17/ift-launche s-global-food-traceability-center.aspx

[91] Report on APEC Regional Study Developing and Applying Traceability System in Agriculture Production and Trade, APEC Agricultural and Technical Cooperation Working Group, December 2009.

[92] The Health Communicator's Social Media Toolkit, Center for Disease Control and Prevention, USA. July 2011. Available: http://www.cdc.gov.

[93] WHO Global Strategy for Food Safety-Safer Food for Better Health. World Health Organization Publication, 2002.

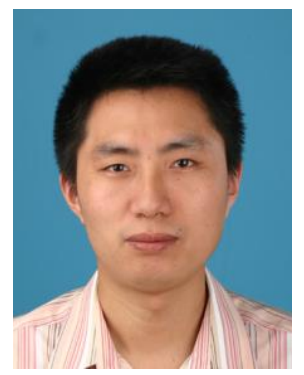

Frank, Jun $\mathrm{Xu}$ is working in the Department of Civil Engineering, The University of Hong Kong, as a post-doctoral fellow. From October 2003 to October 2013, he was a research project manager $\&$ senior information technology manager of the E-Business Technology Institute of the University (ETI/HKU). During the years, he has been involved in the management and development of over ten research and development projects, including projects supported by Innovation and Technology Fund of HKSAR and Guangdong--Hong Kong Technology Cooperation Fund. As a principal investigator, project manager, and technical leader, he is/was responsible for project management, technical management, architecture design, product development, and research of key algorithms in these projects. $\mathrm{He}$ co-authored one patent and four software systems registered at China Copyright Protection Center. Before joining ETI, he worked at several well-known IT companies and research centers of China, serving such technical positions as senior software engineer, system architect and chief technology consultant. His current research interests include but not limited to computing in civil engineering, logistics and supply chain management, internet-of-things, cloud computing, social network, business intelligence, data mining and big data analysis. He earned his $\mathrm{PhD}$ degree in computational mathematics from Peking University in 1998, and his BS degree in applied mathematics from Beijing Institute of Technology in 1995. 


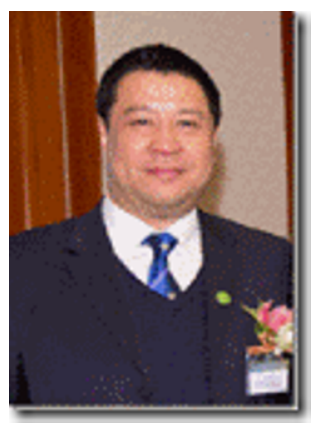

Victor, Zhao Pei is a senior manager (China Research Programs) with the University of Hong Kong and also serves as the senior manager (China Development) at E-Business Solutions Limited (EBS).Mr. Zhao has devoted his efforts on innovative technology to enable enterprises applications and transfer to industrial partners. His area of interest focused on IoT, social network and cloud computing, industrial and logistics solutions in China. Mr. Zhao held BS (Fudan), MS (GWU, USA), MS (HKU). He is also the $\mathrm{PhD}$ candidate of Shanghai University of Finance and Economics.

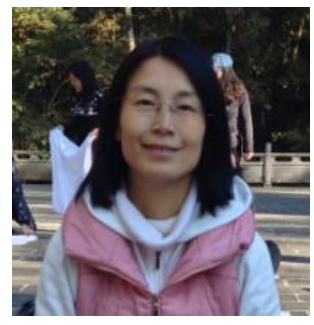

Lu Shan is working at Guangzhou Wanglaoji Pharmaceutical Company Limited, China, responsible for the construction and maintenance of the enterprise applications of the company, such as enterprise portal, attendance system, accounting system and human resource management sytem. She received the degree of Master of Business Administration from Sun Yat-sen University, China. She is a consultant in the implementation of SAP-ABAP, quality management, human resource and business wareshouse.

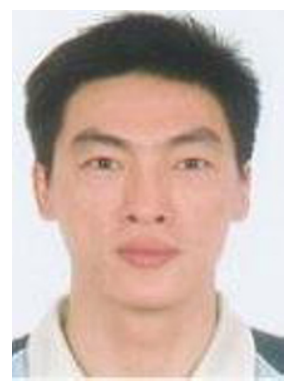

Chuxiong Huang is working with Guangzhou Wanglaoji Pharmaceutical Company Limited, China. As a information technology manager, he is repsonsible for the maintenance and implementation of the enterprise applications of the company, such as financial accounting, controlling, business warehouse, sales and distribution. He has 12 years of experiences in the implementation and deployment of SAP solution. 